\title{
A comparative study of hydroxyapatite coating produced with Plasma Electrolytic Oxidation and Hydrothermal Treatment on Ti alloys: Ti6Al4V and Ti6Al7Nb for dental implants
}

\author{
Elinor Nahum*, Svetlana Lugovskoy \\ Department of Chemical Engineering, Ariel University, Ariel 40700, Israel; svetlanalu@ariel.ac.il \\ * Correspondence: elinorna@ariel.ac.il
}

\begin{abstract}
Ti}$ and $\mathrm{Ti}$ alloys are materials usually used in contact with hard tissue for applications such as artificial joints and dental implants. Ti6Al4V is a very common alloy used for dental implants, owing to its good mechanical properties and corrosion resistance. Nevertheless, because of uncertainties regarding the toxicity of vanadium and its influence on the human body, other Ti alloys containing no vanadium and retaining suitable properties are used. In this work Ti6Al4V and Ti6Al7 Nb were oxidized in a water solution of calcium acetate $\left(\mathrm{Ca}\left(\mathrm{CH}_{3} \mathrm{COO}\right)_{2}\right)$ and calcium glycerophosphate $\left(\mathrm{Ca}\left(\mathrm{PO}_{4} \mathrm{CH}\left(\mathrm{CH}_{2} \mathrm{OH}\right)_{2}\right)\right.$ by Plasma Electrolytic Oxidation (PEO) for 20 minutes and then were hydrothermally treated (HTT) in water $(\mathrm{pH}=7)$ and in potassium hydroxide $(\mathrm{KOH})$ solution ( $\mathrm{pH}=11$ ) for 2 hours at $200^{\circ} \mathrm{C}$ in a pressurized reactor. The surface morphologies, elemental composition and phase components were characterized by Scanning Electron Microscopy (SEM), Energy Dispersive Spectroscopy (EDS) and X-Ray Diffraction (XRD), respectively. The surface roughness was measured by Atomic Force Microscope (AFM) and thickness measurements were made by SEM and thickness gauge. Also, corrosion tests were made to evaluate the corrosion behavior of the two alloys. The aim of this study is to compare two viable Ti alloys, Ti6Al4V and Ti6Al7Nb, and to attain on their surface hydroxyapatite (HA) coating improving the osseointegration, as it simulates a human bone.
\end{abstract}

Keywords: Ti6Al4V; Ti6Al7Nb; Plasma electrolytic oxidation (PEO); hydrothermal treatment (HTT); Hydroxyapatite (HA)

\section{Introduction}

$\mathrm{Ti}$ and Ti alloys are considered perfect materials for applications inside a human body, such as artificial joints, prostheses for blood vessels and dental implants. These alloys have the necessary properties for implant materials, such as low Young modulus, good fatigue strength and excellent corrosion resistance even in aggressive physiological environments. In addition, the corrosion products of $\mathrm{Ti}$ and its alloys are harmless for living tissues and the use of them as bio-medical materials has been increasing significantly in last few decades [1,2]. A layer containing mainly Titania (TiO2) is formed spontaneously or by electrochemical procedures on the surface of $\mathrm{Ti}$ and $\mathrm{Ti}$ alloys. This layer is responsible for the distinctive characteristics of implants materials and thereby is considered to favor their adaptation to living tissues [3]. The most common $\mathrm{Ti}$ alloys used for medical applications are commercial pure Ti (also known as CP-Ti) and Ti6Al4V. CP-Ti cannot be used for medical applications that required high stress durability such as orthopedic prosthesis. It also has poorer mechanical properties than those of other Ti alloys. In the contrary to CP-Ti, Ti6Al4V is an alloy having good corrosion resistance and good mechanical properties, but there are some uncertainties concerning the influence of vanadium, which is considered to be toxic to human body and might be released from the implant due to corrosion and wear processes [4,5]. For that reason, it became necessary to use a vanadium free alloy with suitable properties such as Ti6 $\mathrm{Al} 7 \mathrm{Nb}$ [6]. Ti is a reactive metal which can be easily oxidized when exposed to air or water, producing a thin layer of TiO2. This oxide layer is considered to be passive and chemically stable, it also has the capability of insulate the metal implant from the corrosion environment [7]. The combination of passive oxide 
layers and the smooth surfaces of an untreated metal makes $\mathrm{Ti}$ and $\mathrm{Ti}$ alloys to be bio-inert yet lacking bio-functionality, and therefore to be poorly integrated with bone [8]. To overcome these disadvantages, it is required to modify the surface of the implants. In this study, the surface modification was made by using plasma electrolyte oxidation which is a simple technique for producing hard and rough coating with micro-pores $[9,10]$. Using that technique, the insertion into the coating of such elements as calcium and phosphorous may be performed by just adding them to the electrolyte in a suitable form. The presence of these elements in the coating improves the biological compatibility of the implant to the living body [11]. Also, a PEO coating can reduce metals ion release when compared to uncoated sample [12]. In addition, the coating produced with this technique has good adhesion to the metal even if the implant geometry is complex such as screw shaped implants $[13,14]$. The aim of this study is to compare two viable Ti alloys, Ti6Al4V and Ti6Al7Nb, and to attain on their surface hydroxyapatite (HA) coating improving the osseointegration, as it simulates a human bone.

\section{Materials and Methods}

\subsection{Samples preparation, PEO process and hydrothermal treatment}

Ti6Al4V samples of $40 \mathrm{~mm} \times 20 \mathrm{~mm} \times 1 \mathrm{~mm}$ size and Ti6Al7Nb samples of $40 \mathrm{~mm} \times 20 \mathrm{~mm} \times 3 \mathrm{~mm}$ size were used as substrates in this study. The samples were grounded by 150, 360, 600, 1000 grid silicon carbide $(\mathrm{SiC})$ papers. Subsequently, the samples were cleaned in distilled water and acetone in an ultrasonic cleaner for 5 minutes. The PEO treatment was performed in an electrolyte containing $0.25 \mathrm{M}$ calcium acetate and $0.06 \mathrm{M}$ calcium glycerophosphate in distilled water at current density of $4 \mathrm{~A} / \mathrm{dm} 2$ for 20 minutes. The PEO station was operated in AC mode by the industrial $50 \mathrm{~Hz}$ sine voltage $( \pm 400 \mathrm{~V})$ with a water-cooled stainless-steel container, which served as the counter electrode, equipped with a stirring system. After the completion of the PEO process the samples were washed with distilled water and dried under air. After that, the samples of both alloys were hydrothermally treated in distilled water and in a $\mathrm{KOH}$ solution separately at $200^{\circ} \mathrm{C}$ in a pressurized reactor for 2 hours. The pressure during the treatment was 13-15 bar. In order to double-check the reproducibility of the results, 4-5 samples for used for each kind of treatment.

\subsection{Characterization of the coating}

The surface morphology and elemental composition were characterized by scanning microscope electron (SEM) TESCAN MAIA3 TriglavTM equipped with AZteq Oxford energy dispersive spectroscopy (EDS) analyser. X-Ray diffraction (XRD) Rigaku, SmartLab X-RAY DIFRACTOMETER using Cu-K $\alpha$ radiation $\left(\lambda=1.54 \AA\right.$ ) between $15^{\circ}$ and $65^{\circ}$ angles with a step size $0.02^{\circ}$, was used to characterized the phases components of substrates and coating. Thickness of the coatings was measured by using ElektroPhysik MiniTest 730 thickness gauge based on eddy current principle. The average thickness was taken from ten measurements and the standard deviation was calculated by the device. Focused ion beam technique (FIB) FEI Helios NanoLab ${ }^{\text {TM }} 600$ DualBeam was used to provide a cross sectional area, then coating morphology and thickness were characterize by SEM. Surface roughness of the samples was evaluated with atomic force microscope (AFM) Bruker Dimension FastScan with ScanAsystTM using contact mode.

\subsection{Electrochemical characterization}

The corrosion resistance was determined by electrochemical methods: linear polarization (LPR) and Tafel slopes analyses using a three electrodes corrosion cell in a single chamber, where $\mathrm{Ag} / \mathrm{AgCl}$ electrode functioned as a reference electrode, the sample functioned as the working electrode and a platinum wire as a counter electrode. The processes were operated by an IVIUMnSTAT potentiostat. In order to simulate the physiological conditions of a human body, all corrosion tests were made in a 
Hanks' solution and a simulated saliva solution, whose chemical compositions are given in Table 1. The $\mathrm{pH}$ of the electrolytes was 7 and the temperature was maintained at $36.5^{\circ} \mathrm{C}$.

Table 1. Chemical composition of Hank's and simulated saliva solutions

\begin{tabular}{cccc}
\hline & Hanks' solution [15] & \multicolumn{2}{c}{ Saliva solution [16] } \\
\hline Reagent & Composition [g/l] & Reagent & Composition [g/l] \\
\hline $\mathrm{CaCl}_{2} \cdot 2 \mathrm{H}_{2} \mathrm{O}$ & 0.185 & $\mathrm{MgCl} \cdot 6 \mathrm{H}_{2} \mathrm{O}$ & 0.059 \\
$\mathrm{MgSO}_{4}$ & 0.09767 & $\mathrm{KCl}$ & 0.625 \\
$\mathrm{KCl}$ & 0.4 & $\mathrm{KH}_{2} \mathrm{PO}_{4}$ & 0.326 \\
$\mathrm{KH}_{2} \mathrm{PO}_{4}$ & 0.06 & $\mathrm{~K}_{2} \mathrm{HPO}_{4}$ & 0.804 \\
$\mathrm{NaHCO}_{3}$ & 0.35 & $\mathrm{CaCl}_{2} \cdot 2 \mathrm{H}_{2} \mathrm{O}$ & 0.166 \\
$\mathrm{NaCl}$ & 8.0 & $\mathrm{C}_{3} \mathrm{H}_{8} \mathrm{O}_{3}$ & 2.00 \\
$\mathrm{Na}_{2} \mathrm{HPO}_{4}$ & 0.04788 & Sodium Carboxymethyl & 10.0 \\
& & Cellulose & \\
$\mathrm{Glucose}$ & & \\
\hline
\end{tabular}

\section{Results and Discussion}

\subsection{Scanning electron microscope (SEM)}

The surface morphology of the PEO coating of both Ti alloys is shown in Figure 1. This Figure shows typical microstructure of oxide coating produced after PEO process and characterized by micro pores scattered randomly across the surface. Both alloys have similar morphology after this process. Also, cracks can be seen on the surface of the two alloys (more noticeable for Ti6Al4V). This appearance assumed to be related to the high electron beam intensity, especially when capturing high maganification images.

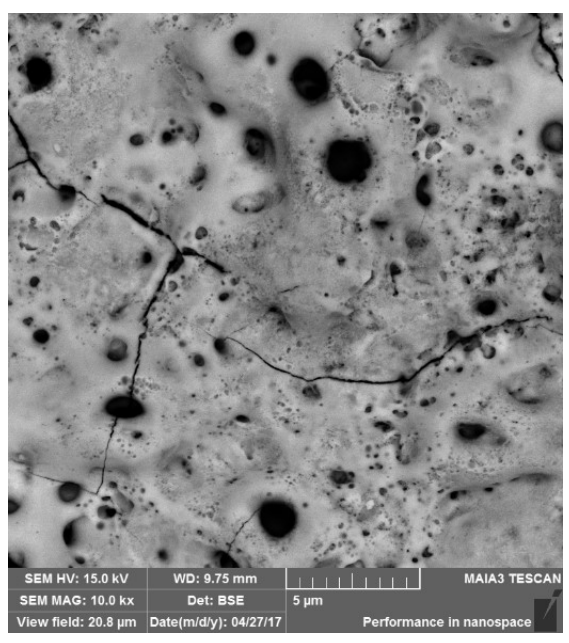

(a)

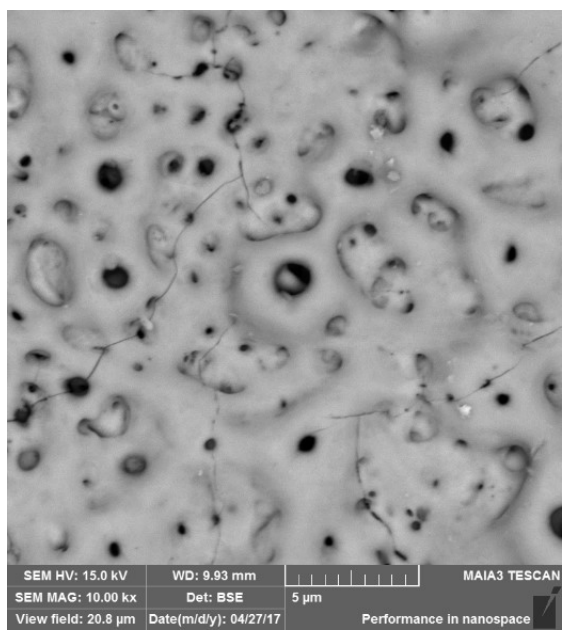

(b)

Figure 1. SEM micrograph of the sample's surface after PEO: (a) Ti6Al4V; (b) Ti6Al7Nb

The surface morphologies were examined after hydrothermal treatment in distilled water $(\mathrm{pH}=7)$ and a $\mathrm{KOH}$ solution $(\mathrm{pH}=11)$, as is shown in Figure 2. After the hydrothermal treatment in distilled water, Ti6Al4V demonstrates a different morphology than Ti6Al7Nb. After that treatment Ti6Al4V surface is characterized by grainy HA crystals on the surface and needle-like HA crystals inside the pores (Figure 2a). On the other hand, the surface of Ti6Al7Nb is mainly characterized by plate-shaped HA crystals localized inside the pores and also needle-like HA crystals localized both 
inside the pores and also on the surface (Figure 2b). For both cases the crystals are distributed uniformly on the surface.

Likewise, after hydrothermal treatment of both alloys in a $\mathrm{KOH}$ solution demonstrate different morphologies. For Ti6Al4V the surface is characterized by an ununiform plate-shaped HA crystals inside the pores and an approximately smooth surface outside the pores with no crystals at all (Figure 2c). In contrast to that, Ti6Al7Nb surface is characterized by an ununiform plate-shaped HA crystals inside the pores and a uniform mixture of grainy and needle-like crystals on the surface (Figure 2d).

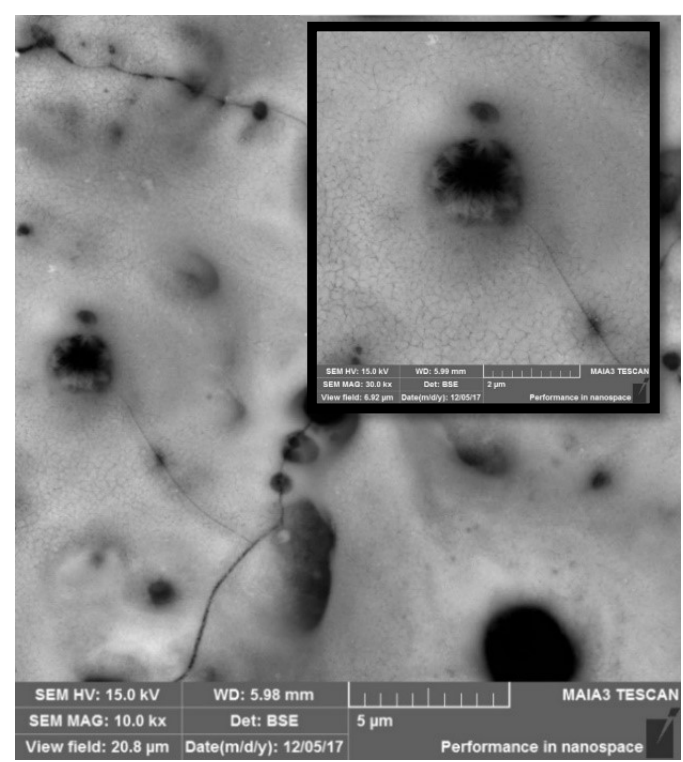

(a)

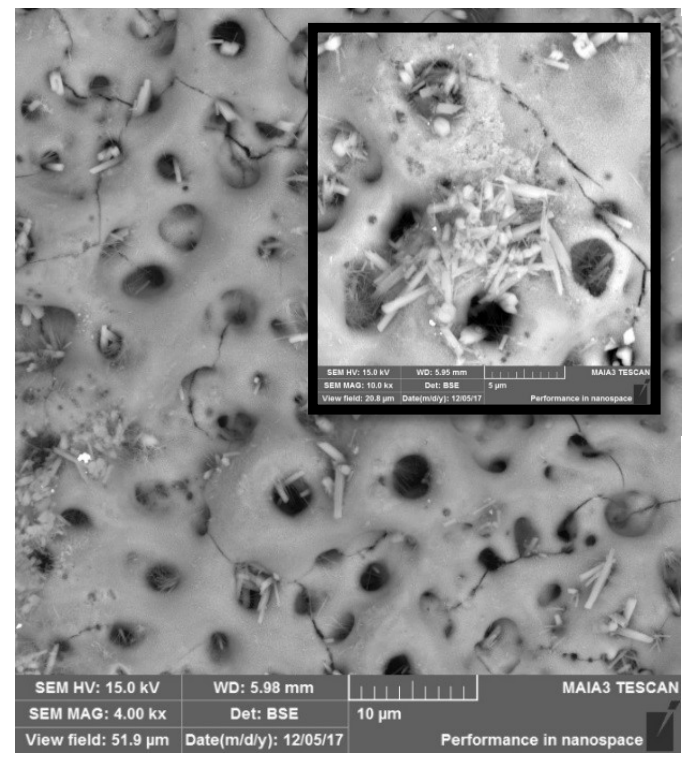

(c)

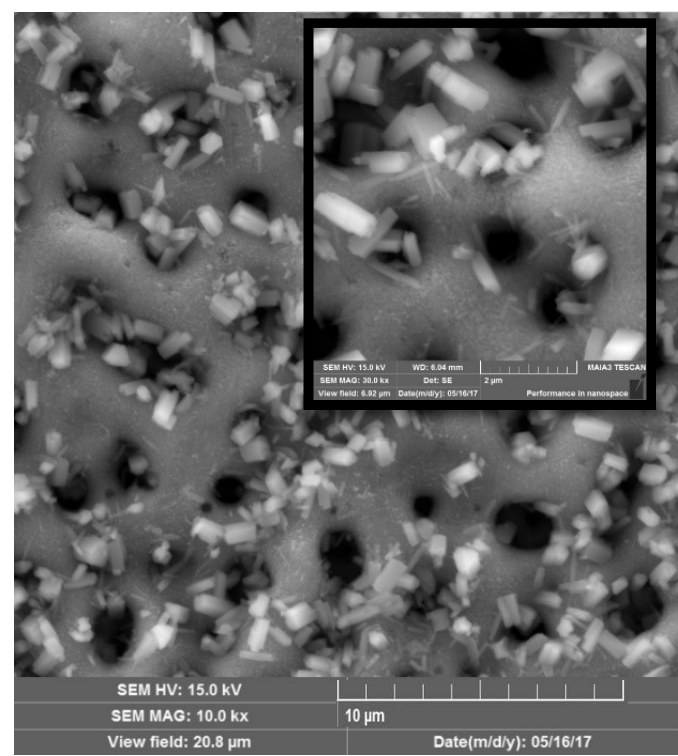

(b)

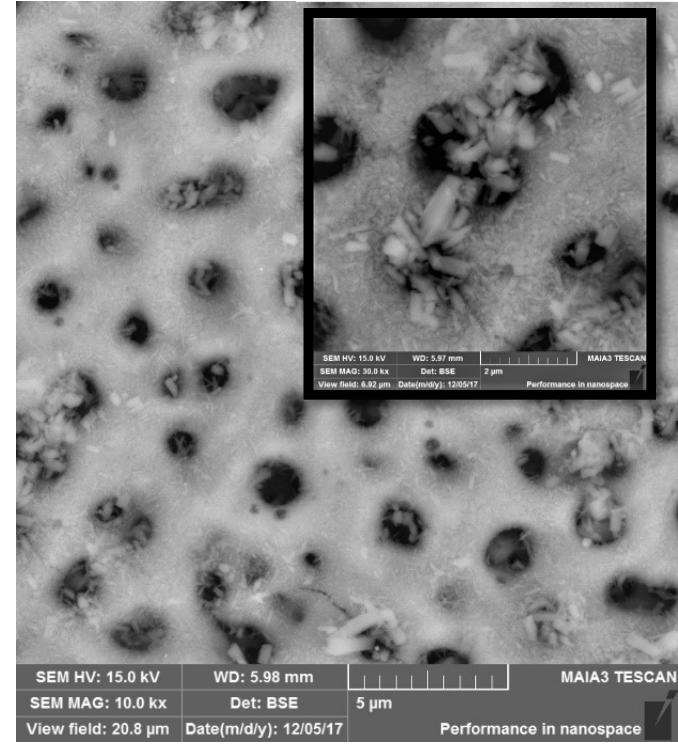

(d)

Figure 2. Surface morphologies of coatings after hydrothermal treatment: (a) Ti6Al4V pH=7; (b) Ti6Al7Nb pH=7; (c) Ti6Al4V pH=11; (d) Ti6Al7Nb pH=11 
The surface morphologies were examined also by SEM images of the alloys after exposing a cross sectional area by FIB. Example for these images is shown in Figure 3.

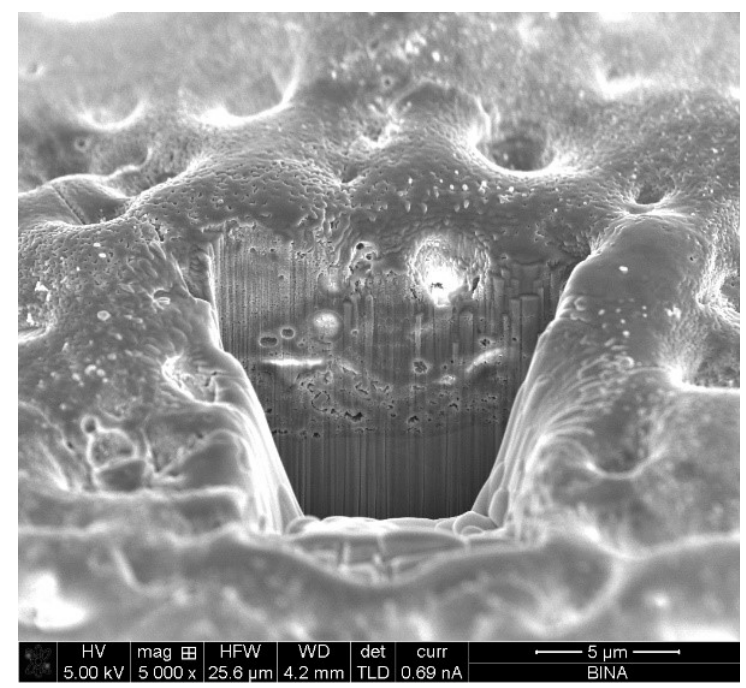

(a)

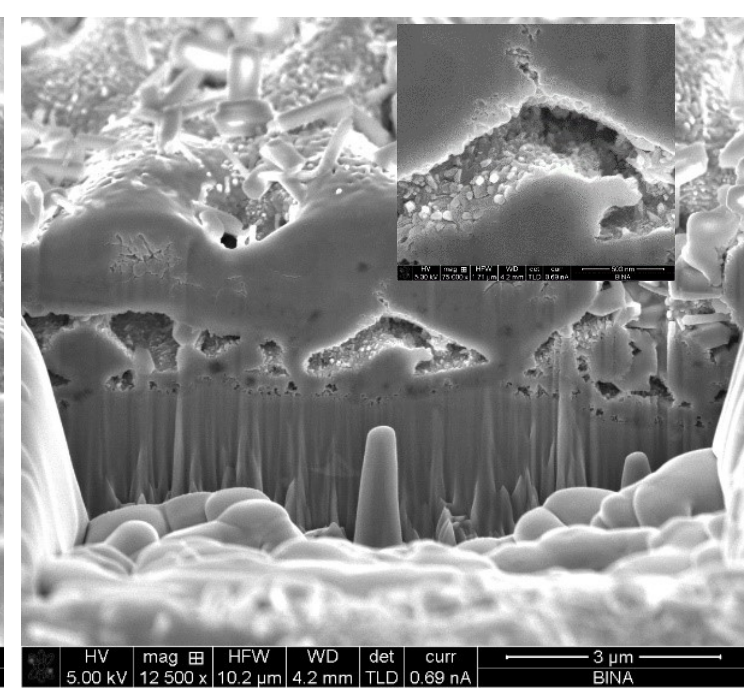

(b)

Figure 3. Surface morphologies of coatings after hydrothermal treatment, $\mathrm{pH}=7$ : (a) Ti6Al4V; (b) Ti6Al7Nb

Figure 3 gives another point of view for surface characterization for both alloys. The surface of Ti6Al4V (Figure 3.a) is characterized by rough surface with grainy HA crystals. Ti6Al7Nb's surface (Figure 3.b) is characterized by plate shaped HA crystals on top of surface and also inside the pores that located deep in the oxide layer. Furthermore, for both alloys, pores can be seen in the cross section of the oxide layer.

\subsection{Energy dispersive spectroscopy (EDS)}

The elemental composition (\%atomic) obtained by EDS spectra is given in Table 2. The presented chemical composition is the average of three-point mode analysis and standard deviation is displayed.

Table 2. Elemental composition (EDS) of coating after PEO and hydrothermal treatments

\begin{tabular}{ccccccccc}
\hline \multirow{2}{*}{ Treatment } & Ti alloy & Ti & Al & Nb/V & O & Ca & P & C \\
\hline PEO & Ti6Al4V & $15.1 \pm 0.1$ & $1.6 \pm 0.0$ & $0.6 \pm 0.0$ & $63.3 \pm 0.2$ & $8.6 \pm 0.0$ & $5.7 \pm 0.0$ & $5.2 \pm 0.1$ \\
& Ti6Al7Nb & $10.5 \pm 0.5$ & $1.2 \pm 0.0$ & $0.4 \pm 0.0$ & $58.1 \pm 0.6$ & $7.5 \pm 0.1$ & $4.6 \pm 0.0$ & $17.8 \pm 1.2$ \\
HTT pH=7 & Ti6Al4V & $17.7 \pm 1.9$ & $1.9 \pm 0.0$ & $0.3 \pm 0.2$ & $64.8 \pm 0.6$ & $7.2 \pm 0.4$ & $4.4 \pm 0.2$ & $3.8 \pm 0.4$ \\
& Ti6Al7Nb & $17.9 \pm 0.3$ & $2.2 \pm 0.1$ & $0.7 \pm 0.1$ & $69.8 \pm 0.0$ & $5.0 \pm 0.3$ & $4.6 \pm 0.1$ & - \\
HTT pH=11 & Ti6Al4V & $15.5 \pm 4.6$ & $1.6 \pm 0.7$ & $0.4 \pm 0.1$ & $59.9 \pm 7.7$ & $11.6 \pm 8.5$ & $5.8 \pm 3.4$ & $5.5 \pm 1.4$ \\
& Ti6Al7Nb & $14.5 \pm 3.4$ & $2.1 \pm 0.6$ & $0.6 \pm 0.0$ & $65.3 \pm 5.3$ & $6.1 \pm 3.7$ & $5.1 \pm 1.9$ & $6.4 \pm 1.7$ \\
\hline
\end{tabular}

Table 2 shows that the coating contains mainly $\mathrm{Ti}$ and oxygen as it is a film of Ti oxide. there also are some additional elements like aluminum and vanadium or niobium, which are originated from the substrates, and calcium, phosphorus and carbon originated from the electrolyte. 


\subsection{X-Ray diffraction (XRD)}

Figure 4 shows XRD spectra of the surface film for substrates and different treatments. It can be seen that for both alloys there is no presence of HA after PEO but it does appear after both kinds of the hydrothermal treatments. additionally, an amorphous phase is present after PEO for both alloys, but not after the hydrothermal treatments. The phase compositions are summarized in Table 3. The presence of HA in the coatings after HTT is very significant as it integrates well with living bone tissues and it has been widely used as bone replacement material in dental implants field [17].

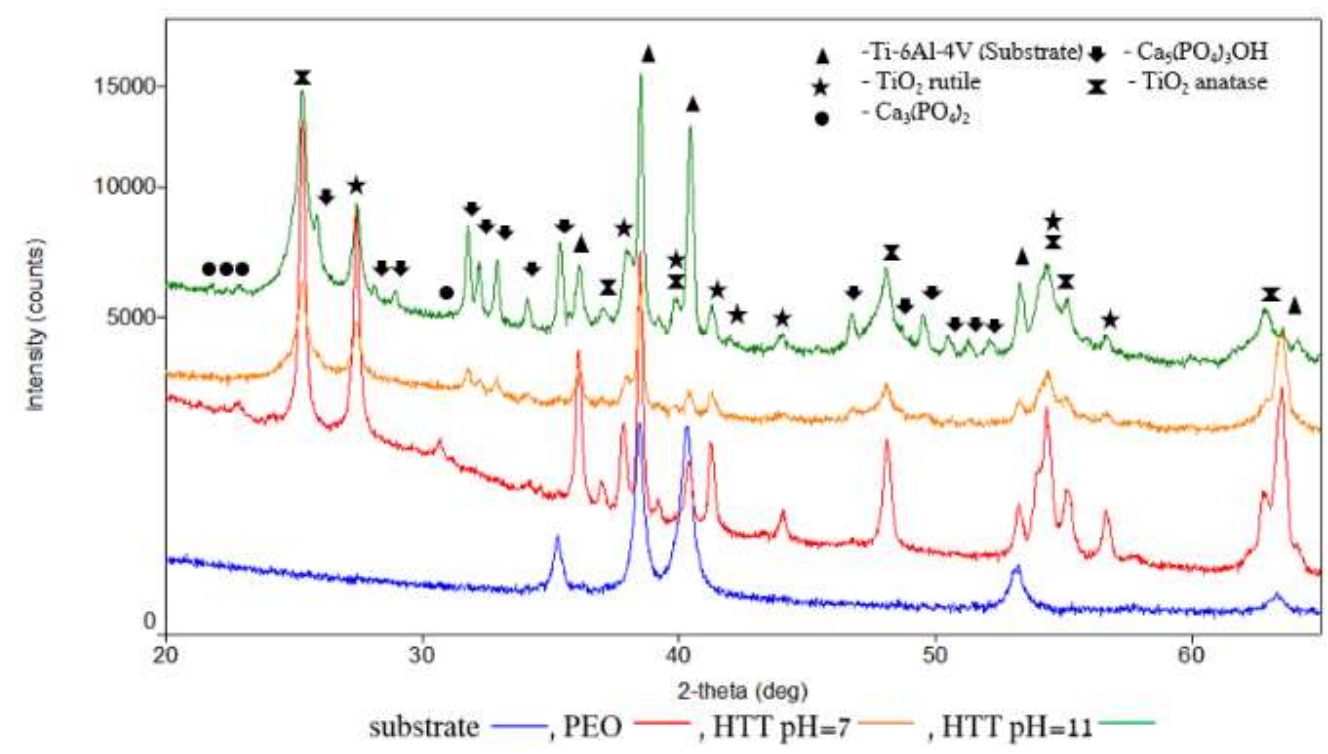

(a)

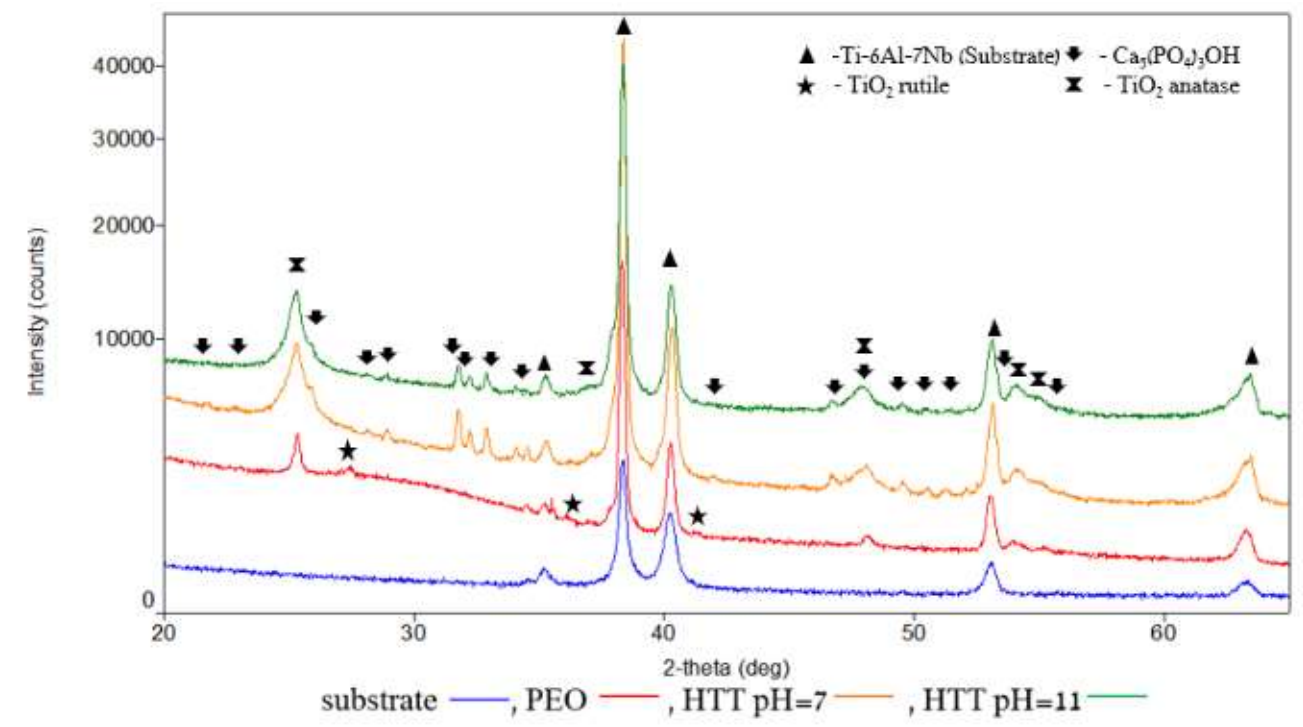

(b)

Figure 4. XRD spectra acquired from the coatings: (a) Ti-6Al-4V and (b) Ti-6Al-7Nb 
Table 3. Phase composition of coating after PEO and hydrothermal treatments

\begin{tabular}{lll}
\hline \multicolumn{1}{c}{ Treatment } & \multicolumn{1}{c}{ Ti6Al7Nb } & \multicolumn{1}{c}{ Ti6A14V } \\
\hline PEO & $\mathrm{TiO}_{2}$ - rutile, anatase & $\mathrm{TiO}_{2}$ - rutile, anatase \\
& Amorphous phase & $\mathrm{Ca}_{3}\left(\mathrm{PO}_{4}\right)_{2}$ \\
& & $\mathrm{Amorphous}$ phase \\
$\mathrm{HTT} \mathrm{pH}=7$ & $\mathrm{TiO}_{2}$-anatase & $\mathrm{TiO}_{2}$ - rutile, anatase \\
& $\mathrm{HA}$ & $\mathrm{HA}$ \\
$\mathrm{HTT} \mathrm{pH}=11$ & $\mathrm{TiO}$-anatase & $\mathrm{TiO}_{2}$ - rutile, anatase \\
& $\mathrm{HA}$ & $\mathrm{HA}$ \\
\hline
\end{tabular}

\subsection{Coating thickness measurements}

The thickness of the coating was determined by two different methods (Table 4): (a) by using a thickness gauge and (b) by using a scanning electron microscope after exposing a cross sectional area by FIB. The measurements reveal a higher coating thickness for Ti6Al4V than Ti6Al7Nb. In addition, a higher standard deviation was found for Ti6Al4V coating which shows ununiform thickness for Ti6Al4V and a thin uniform coating for Ti6Al7Nb.

Table 4. Thickness of the coatings on Ti alloys

\begin{tabular}{cccc}
\hline Ti alloy & Treatment & $\begin{array}{c}\text { Average coating } \\
\text { thickness by SEM }[\mu \mathrm{m}]\end{array}$ & $\begin{array}{c}\text { Method } \\
\text { Average coating thickness by } \\
\text { thickness gauge }[\mu \mathrm{m}]\end{array}$ \\
\hline Ti6Al4V & PEO & $6.4 \pm 1.2$ & $9.4 \pm 1.0$ \\
& HTT pH=7 & $8.5 \pm 1.0$ & $8.8 \pm 1.1$ \\
& HTT $\mathrm{pH}=11$ & $7.0 \pm 0.9$ & $9.5 \pm 1.2$ \\
Ti6Al7Nb & PEO & $2.8 \pm 0.4$ & $2.8 \pm 0.3$ \\
& HTT $\mathrm{pH}=7$ & $3.2 \pm 0.1$ & $2.4 \pm 0.2$ \\
& HTT $\mathrm{pH}=11$ & $3.0 \pm 0.6$ & $2.6 \pm 0.4$ \\
\hline
\end{tabular}

\subsection{Roughness measurements by AFM}

3D AFM images of Ti6Al4V and Ti6Al7Nb after PEO and hydrothermal treatments are shown in Figure 5. The area that was scanned was $5 \mu \mathrm{m} \times 5 \mu \mathrm{m}$ and three areas were scanned. The values of average roughness $\left(R_{a}\right)$ are listed in Table 5 . $R_{a}$ values are higher for Ti6Al7Nb for all treatments and these results support AFM and SEM images, which exhibit a developed surface with plate-shaped HA crystals inside pores and grainy crystals on the surface. Roughness values between $10 \mathrm{~nm}$ to $10 \mu \mathrm{m}$ may control the interface biology, due to the fact that it is of the same order in size as small cells and large biomolecules [18]. Also, roughness has a significant influence on bone tissue reaction and may enhance bone-to-implant contact [19]. 


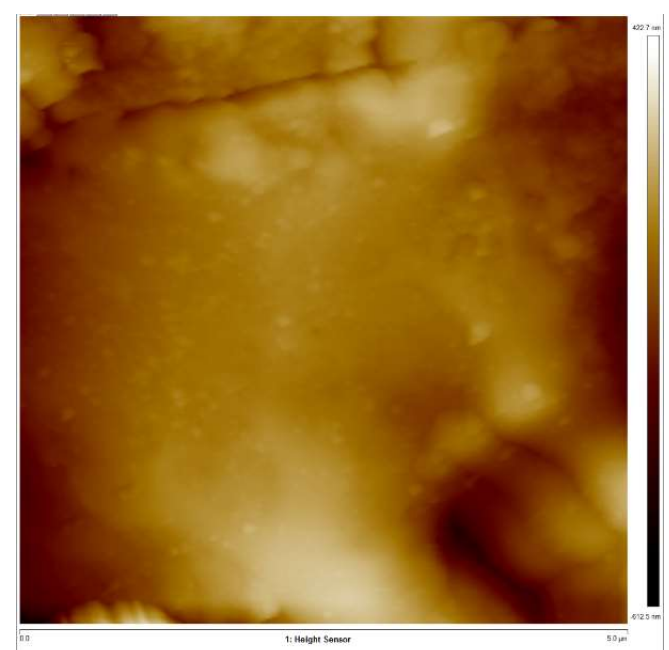

(a)

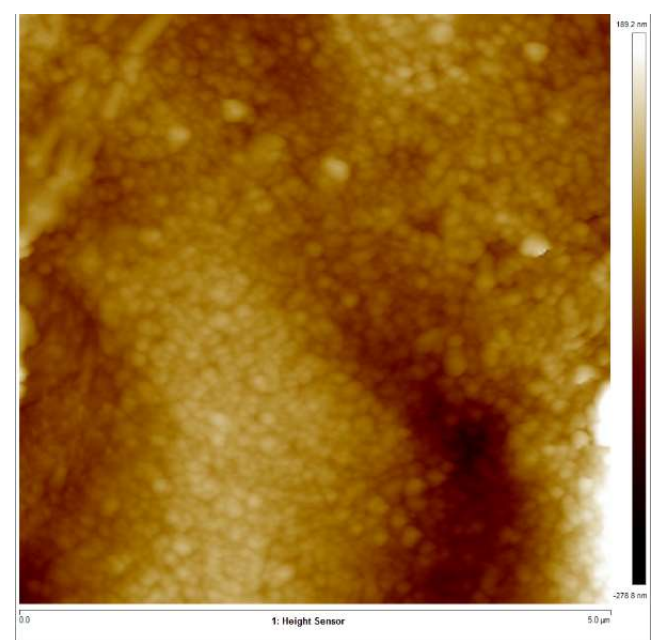

(c)

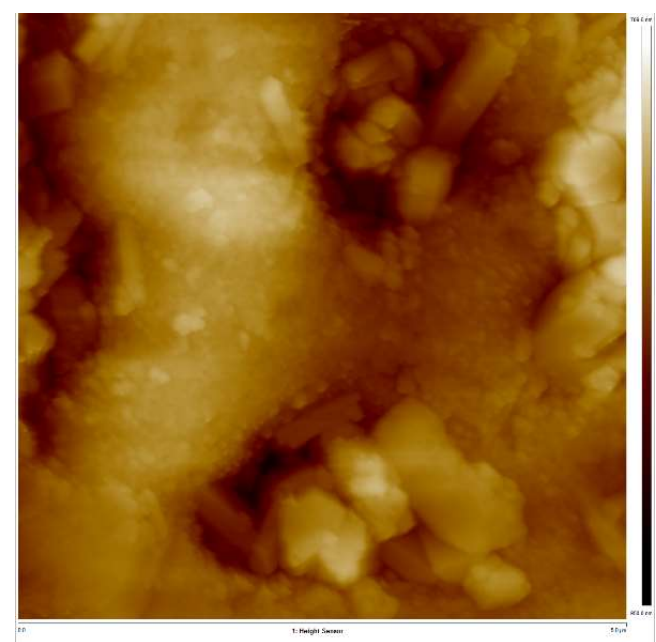

(e)

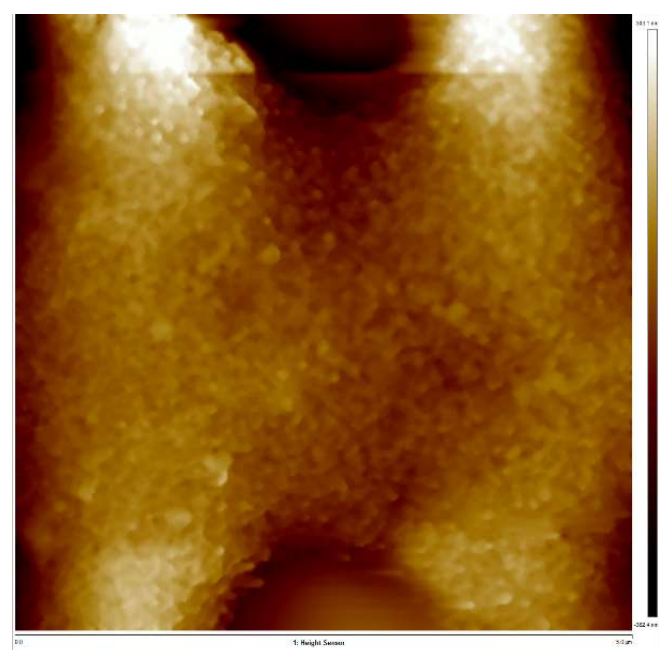

(b)

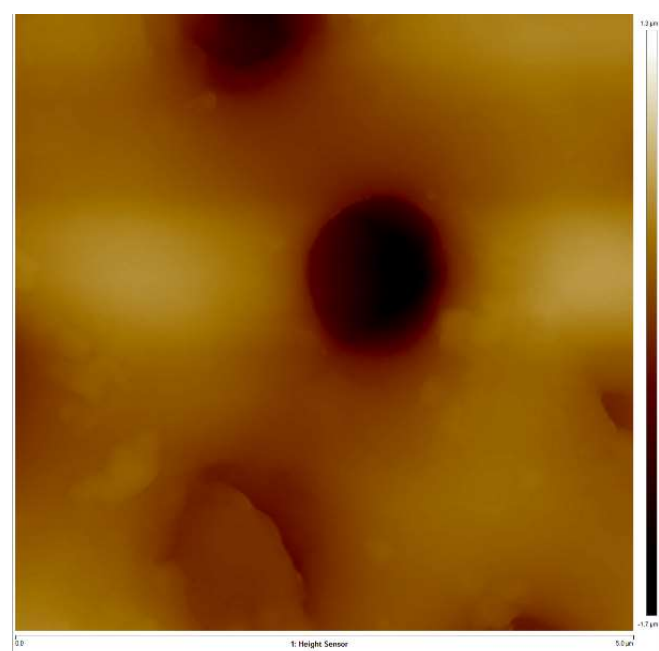

(d)

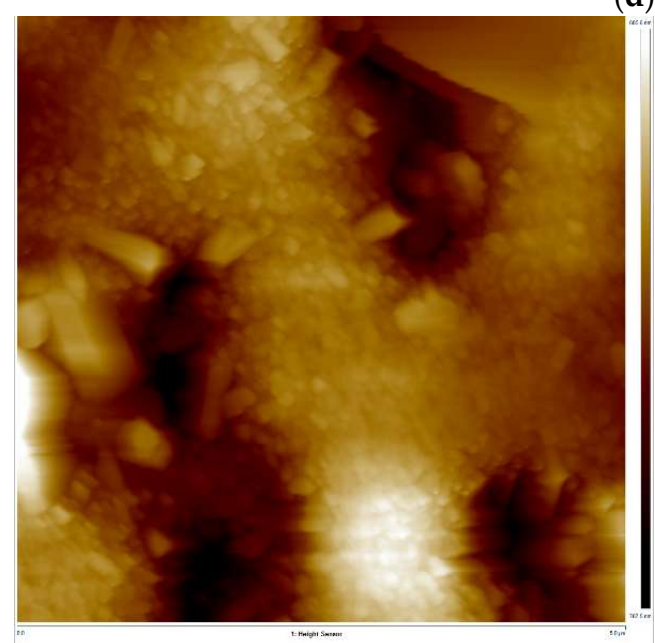

(f)

Figure 5.3D AFM images: (a) Ti6Al4V after PEO; (b) Ti6Al4V after HTT pH=7; (c) Ti6Al4V after HTT pH=11; (d) Ti6Al7Nb after PEO; (e) Ti6Al7Nb after HTT pH=7; (f) Ti6Al7Nb after HTT pH=11 
Table 5. Ra values for Ti6Al4V and Ti6Al7Nb surface after PEO and hydrothermal treatments

\begin{tabular}{ccc}
\hline Ti alloy & Treatment & $\mathbf{R}_{\mathbf{a}}[\mathbf{n m}]$ \\
\hline Ti6Al4V & PEO & 83.1 \\
& $\mathrm{HTT} \mathrm{pH}=7$ & 115.7 \\
& $\mathrm{HTT}$ pH=11 & 55.4 \\
& PEO & 232.7 \\
Ti6Al7Nb & HTT pH=7 & 175.3 \\
& HTT $\mathrm{pH}=11$ & 234.7 \\
\hline
\end{tabular}

\subsection{Electrochemical characterization}

Polarization curves were measured between $\pm 250 \mathrm{mV}$ at the scan rate of $1 \mathrm{mV} / \mathrm{s}$ and linear polarization measurements (LPR) were performed in a range of $\pm 10 \mathrm{mV}$ at the scan rate of $0.5 \mathrm{mV} / \mathrm{s}$. Corrosion parameters such as $\mathrm{J}_{\text {corr- }}$ current density; Icorr-corrosion current and $\mathrm{R}_{\mathrm{p}}$ corrosion resistance were evaluated (Table 6). It can be seen from Table 6 that the corrosion currents are significantly small and the corrosion resistance is significantly high, as it is known for Ti alloys and Ti oxide. Furthermore, passivation is observed for Ti6Al7Nb in both solutions.

Table 6. Corrosion parameters for Ti6Al4V and Ti6Al7Nb in Hanks' and saliva solution

\begin{tabular}{|c|c|c|c|c|c|c|c|}
\hline $\begin{array}{c}\text { Ti alloy and } \\
\text { treatment }\end{array}$ & Solution & \multicolumn{3}{|c|}{ LPR } & \multicolumn{3}{|c|}{ Tafel } \\
\hline \multicolumn{2}{|c|}{ Parameters } & Jcorr & Icorr & $\mathbf{R}_{\mathrm{p}}[\Omega]$ & Jcorr & $I_{\text {corr }}$ & $\mathbf{R}_{\mathrm{p}}[\Omega]$ \\
\hline & & {$\left[\mathrm{A} / \mathrm{cm}^{2}\right]$} & [A] & & {$\left[\mathrm{A} / \mathrm{cm}^{2}\right]$} & [A] & \\
\hline \multirow[t]{2}{*}{ Ti6Al4V PEO } & Hanks' & $3.76 \cdot 10^{-7}$ & $3.58 \cdot 10^{-7}$ & $1.57 \cdot 10^{5}$ & $2.31 \cdot 10^{-7}$ & $2.19 \cdot 10^{-7}$ & $2.57 \cdot 10^{5}$ \\
\hline & Saliva & $2.91 \cdot 10^{-8}$ & $2.76 \cdot 10^{-8}$ & $8.71 \cdot 10^{4}$ & $2.63 \cdot 10^{-8}$ & $2.50 \cdot 10^{-8}$ & $9.28 \cdot 10^{4}$ \\
\hline \multirow[t]{2}{*}{ Ti6Al7Nb PEO } & Hanks' & $2.66 \cdot 10^{-6}$ & $2.53 \cdot 10^{-6}$ & $2.27 \cdot 10^{4}$ & $1.32 \cdot 10^{-6}$ & $1.26 \cdot 10^{-6}$ & $4.57 \cdot 10^{4}$ \\
\hline & Saliva & - & - & $1.43 \cdot 10^{6}$ & & passivation & \\
\hline Ti6Al4V HTT & Hanks' & $5.16 \cdot 10^{-7}$ & $4.90 \cdot 10^{-7}$ & $7.95 \cdot 10^{4}$ & $2.83 \cdot 10^{-7}$ & $2.69 \cdot 10^{-7}$ & $1.45 \cdot 10^{5}$ \\
\hline $\mathrm{pH}=7$ & Saliva & $2.06 \cdot 10^{-7}$ & $1.96 \cdot 10^{-7}$ & $1.96 \cdot 10^{5}$ & $1.02 \cdot 10^{-7}$ & $9.68 \cdot 10^{-8}$ & $3.95 \cdot 10^{5}$ \\
\hline Ti6Al7Nb HTT & Hanks' & - & - & $1.48 \cdot 10^{5}$ & & passivation & \\
\hline $\mathrm{pH}=11$ & Saliva & - & - & $4.76 \cdot 10^{5}$ & & passivation & \\
\hline Ti6Al4V HTT & Hanks' & $1.38 \cdot 10^{-6}$ & $1.31 \cdot 10^{-6}$ & $3.62 \cdot 10^{4}$ & $1.23 \cdot 10^{-6}$ & $1.17 \cdot 10^{-6}$ & $4.06 \cdot 10^{4}$ \\
\hline $\mathrm{pH}=7$ & Saliva & $2.44 \cdot 10^{-7}$ & $2.32 \cdot 10^{-7}$ & $1.92 \cdot 10^{5}$ & $1.30 \cdot 10^{-7}$ & $1.24 \cdot 10^{-7}$ & $3.61 \cdot 10^{5}$ \\
\hline Ti6Al7Nb HTT & Hanks' & - & - & $1.15 \cdot 10^{6}$ & & passivation & \\
\hline $\mathrm{pH}=11$ & Saliva & - & - & $1.22 \cdot 10^{6}$ & & passivation & \\
\hline
\end{tabular}

Examples for Tafel plots for both alloys after HTT in distilled water are shown in Figure 6. Passivation is observed for Ti6Al7Nb (Figure 6.b). 


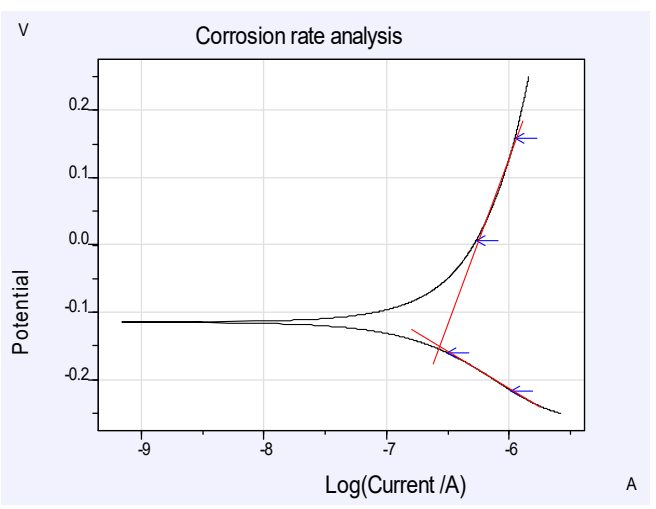

(a)

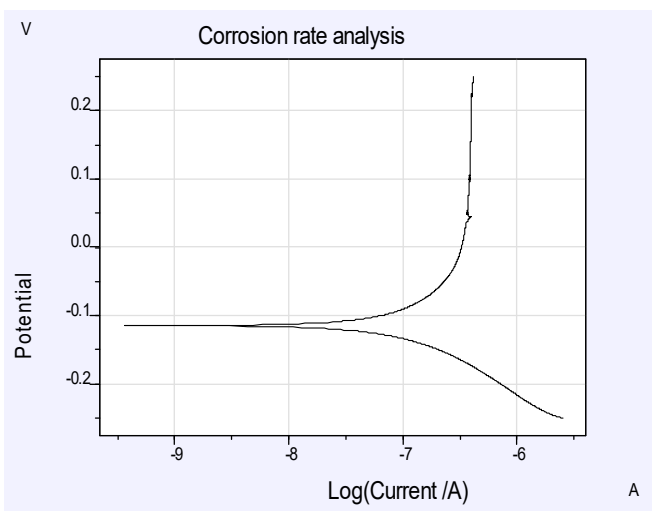

(b)

Figure 6. Tafel plots for: (a) Ti6Al4V after HTT pH=7 in Hanks' solution; (b) Ti6Al7Nb after HTT $\mathrm{pH}=7$ in in Hanks' solution

\section{Conclusions}

Ti6Al4V and Ti6Al7Nb alloys were characterized in terms of surface morphologies, elemental and phase's composition, coating thickness, roughness and corrosion behavior after treated by PEO and hydrothermally.

- According to the results of this study, the Ti6Al7Nb alloy may be preferred over Ti6Al4V, thereby avoiding the use of vanadium toxicity.

- Hydroxyapatite-containing surfaces can be attained by the two-stage procedure, PEO and HTT, for both alloys.

- Using the same parameters, different coating thicknesses are attained for the two competing alloys. For Ti6Al4V the thickness is not even as compared to Ti6Al7Nb.

- The most developed surface with plate-shaped HA crystals was obtained for Ti6Al7Nb after HTT in distilled water.

- The surface roughness increased after PEO for both alloys, although the roughness of Ti6Al7Nb is higher.

- Corrosion tests showed passivation for all samples of Ti6Al7Nb after were treated hydrothermally on both solutions.

\section{References}

1. Srimaneepong, V.; Yoneyama, T.; Kobayashi, E.; Doi, H.; Hanawa, T. Comparative study on torsional strength, ductility and fracture characteristics of laser-welded $\alpha+\beta$ Ti-6Al-7Nb alloy, CP Ti and Co-Cr alloy dental castings. Dent. Mater, 2008, 24, 839-845, DOI: 10.1016/j.dental.2007.10.002.

2. Lugovskoy, A.; Lugovskoy,S. Production of hydroxyapatite layers on the plasma electrolytically oxidized surface of Ti alloys. Mater. Sci. Eng, 2014, C. 43, 527-532, DOI:10.1016/j.msec.2014.07.030.

3. Pan, J.; Thierry, D.; Leygraf, C. Electrochemical impedance spectroscopy study of the passive oxide film on Ti for implant application. Electrochim Acta 1996, 41, 1143-53.

4. Okazaki, Y.; Ito, Y.; Kyo, K.; Tateishi, T. Corrosion resistance and corrosion fatigue strength of new Ti alloys for medical implants without $\mathrm{V}$ and $\mathrm{Al}$, Mater. Sci. Eng. 1996, A. 213, 138-147, DOI:10.1016/0921-5093(96)10247-1.

5. Elias, C.N.; Fernandes, D.J.; Resende, C.R.S.; Roestel, J. Mechanical properties, surface morphology and stability of a modified commercially pure high strength Ti alloy for dental implants. Dent. Mater. 2015, 31, e1-e13, DOI:10.1016/j.dental.2014.10.002.

6. Tamilselvi, S.; Raman, V.; Rajendran, N.; Corrosion behaviour of Ti-6Al-7Nb and Ti-6Al-4V ELI alloys in the simulated body fluid solution by electrochemical impedance spectroscopy. Electrochim. Acta. 2006, 52, 839-846, DOI:10.1016/j.electacta.2006.06.018.

7. Rajapakse, R.M.G.; Wijesinghe, W.P.S.L. Preparation of bone-implants by coating hydroxyapatite nanoparticles on self-formed Ti dioxide thin-layers on Ti metal surfaces. Mater. Sci. Eng. 2016, C. 63, $172-$ 184, DOI:10.1016/j.msec.2016.02.053. 
8. Adeleke, S.A.; Sopyan, I.; Bushroa, A.R. Hydroxyapaptite Layer Formation on Ti Alloys Surface Using Micro-Arc Oxidation. ARPN J. Eng. Appl. Sci. 2015, 10, 10101-10108.

9. Ibrahim, M.Z.; Sarhan, A.A.D.; Yusuf, F.; Hamdi, M. Biomedical materials and techniques to improve the tribological, mechanical and biomedical properties of orthopedic implants - A review article. J. Alloys Compd 2017, 714, 636-667, DOI:10.1016/j.jallcom.2017.04.231.

10. Qingbiao, L.; Jun, L.; Qing, W. Plasma Electrolytic Oxidation Coatings on Lightweight Metals. In Modern Surface Engineering Treatments, Aliofkhazraei, M., Publisher: 32 London Bridge Street, UNITED KINGDOM, 2013, Volume 3, pp. 75-99; ISBN: 978-953-51-1149-8.

11. Kossenko, A.; Lugovskoy, S.; Astashina, N.; Lugovskoy, A.; Zinigrad, M. Effect of Time on the Formation of Hydroxyapatite in PEO Process with Hydrothermal Treatment of the Ti-6Al-4V Alloy. Glas. Phys. Chem, 2013, 39, 639-642, DOI:10.1134/S1087659613060072.

12. Mohedano, M.; Matykina, E.; Arrabal, R.; Pardo, A.; Merino, M.C. Metal release from ceramic coatings for dental implants. Dental Materials, 2014, 30, e28-e40, DOI: https://doi.org/10.1016/j.dental.2013.12.011.

13. Esen, Z; Öcal, E.B. Surface characteristics and in-vitro behavior of chemically treated bulk Ti6Al7Nb alloys. Surf. Coatings Technol, 2017, 309, 829-839, DOI:10.1016/j.surfcoat.2016.10.078.

14. Zhu, X.; Chen, J.; Scheideler, L.; Reichl, R.; Geis-Gerstorfer, J. Effects of topography and composition of Ti surface oxides on osteoblast responses. Biomaterials, 2004 ,25, 4087-4103, DOI:10.1016/j.biomaterials.2003.11.011.

15. SIGMA- ALDRICH

Available online: https://www.sigmaaldrich.com/content/dam/sigma-aldrich/docs/Sigma/Formulation/d5796for.pdf.

16. PICKERING LABORATORIES. Available online: https://www.pickeringlabs.com/wp-content/uploads/sds/SDS\%201700 0305\%20Artificial\%20Saliva\%20for\%20Medical\%20and\%20Dental\%20Research.pdf

17. Gu, Y.W.; Khor, K.A.; Cheang, P. Bone-like apatite layer formation on hydroxyapatite prepared by spark plasma sintering. Biomaterials, 2004, 25, 4127-4134.

18. Dilea, M.; Mazare, D.; Ionita, D.; Demetrescu, I. Comparison between corrosion behavior of implant alloys Ti6Al7Nb and Ti6Al4Zr in artificial saliva. Materials and Corrosion, 2013, 64, 493-499. DOI: 10.1002/maco.201206526.

19. Carlos, N.E.; Luiz, M. Improving osseointegration of dental implants. Expert Rev. Med. Devices, 2010, 7(2), 241-256. 